\title{
KARAKTERISASI MINYAK JELANTAH HASIL PRODUKSI KERIPIK NENAS DENGAN METODE VACUUM FRYING
}

\author{
Rusdianasari $^{1)}$, Leila Kalsum ${ }^{1)}$, Aida Syarif ${ }^{1)}$, Yohandri Bow ${ }^{2)}$ \\ ${ }^{1}$ Program Studi Teknik Energi Terbarukan, Jurusan Teknik Kimia, Politeknik Negeri Sriwijaya \\ ${ }^{2}$ Program Studi Teknik Energi, Jurusan Teknik Kimia, Politeknik Negeri Sriwijaya \\ email: rusdianasari@polsri.ac.id, elak87chem@yahoo.com, aida_syarif@yahoo.co.id, \\ yohandribow@polsri.ac.id
}

\begin{abstract}
Small and medium businesses (SMEs) have developed rapidly in Indonesia, especially for the food sector. One of the most productive UKM in Prabumulih city is UKM Melati which produces pineapple chips from pineapple which is a regional superior product from Prabumulih city. To get dried and tasty pineapple chips, frying is done by using a vacuum frying method that requires a lot of cooking oil. The results of vacuum drying frying will produce used browning frying oil or used cooking oil and cannot be reused if the characteristics of used cooking oil exceed the standard. For this reason, an analysis is needed to determine the characteristics of used cooking oil from the results of the production of pineapple chip vacuum vacuum frying methods. From the results of the analysis that has been carried out on filtered used cooking oil, the value of free fatty acid (FFA) is $4.9 \%$ (maximum requirement $0.3 \%$ ) and peroxide value $1.8 \mathrm{Meq} / \mathrm{kg}$. Thus, used cooking oil cannot be used anymore for frying.
\end{abstract}

Keywords: minyak jelantah, karakterisasi, keripik nenas

\section{PENDAhUluan}

Minyak jelantah adalah minyak minyak bekas hasil penggorengan makanan yang tekah dipakai berulang kali, baik hasil penggorengan di rumah tangga maupun dari pusat jajanan ataupun rumah makan [1-4]. Minyak jelantah termasuk golongan minyak nabati yang berasal dari minyak kelapa dan minyak kelapa sawit. Konsumsi rata-rata minyak goreng di Indonesia selama tahun 2009-2013 telah mencapai $10,17 \mathrm{~kg}$ per kapita [5]. Dari nilai konsumsi tersebut, diperkirakan jumlah minyak jelantah yang berasal dari penggunaan rumah tangga dan rumah makan mencapai 3,88 juta ton per tahun [6].

Akibat dari pemanasan yang berulang, maka penggunaan minyak jelantah akan membahayakan kesehatan manusia dikarenakan minyak jelantah tersebut mengandung beberapa senyawa yang berbahaya antara lain polimer, aldehid, asam lemak bebas, dan senyawa aromatik [7]. Tabel 1 menunjukkan data parameter dari minyak jelantah. Penggunaan minyak jelantah hanya diperbolehkan sampai empat kali pemakaian karena setelah dilakukan pemanasan berulang akan menghasilkan radikal bebas yang dapat menyebabkan penyakit kanker [8].

Tabel 1. Data Parameter Minyak Jelantah [4]

\begin{tabular}{clc}
\hline No. & \multicolumn{1}{c}{ Parameter } & Nilai \\
\hline 1. & Berat jenis, gr/liter & 0,9104 \\
2. & Viskositas kinematik & 39,07 \\
& $40^{\circ} \mathrm{C}, \mathrm{cSt}$ & \\
3. & Bilangan asam, mg- & 1,0037 \\
& KOH/gr sampel & \\
4. & Kadar air, \%-volume & 1,24 \\
5. & Bilangan peroksida, mg & 0,0168 \\
& $\mathrm{O}_{2} / 100 \mathrm{gr}$ & \\
6. & Titik nyala, ${ }^{\circ} \mathrm{C}$ & 247,7 \\
\hline
\end{tabular}

Keripik nenas dibuat dengan bahan baku buah nenas yang dikupas dan dipotongpotong kemudian digoreng dengan menggunakan vacuum frying agar diperoleh keripik nenas yang renyah dan gurih. Untuk menggoreng nenas menjadi keripik nenas dengan vacuum frying memerlukan minyak goreng yang banyak sekali sehingga hasilproduksi akan menghasilkan minyak jelantah dalam jumlah yang banyak. 


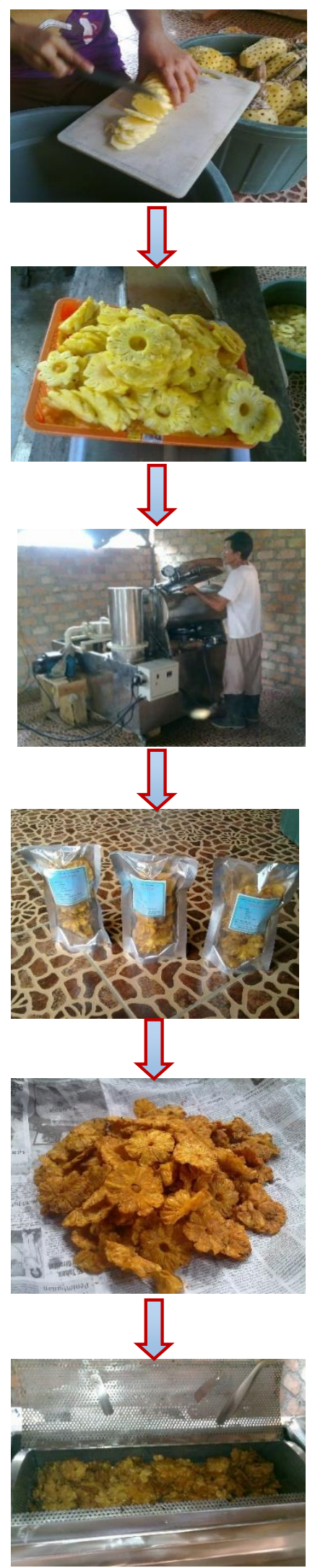

Gambar 1. Proses pembuatan keripik nenas dengan vacuum frying

\section{IDENTIFIKASI MASALAH}

UKM UP2K Melati merupakan suatu wadah usaha dari Organisasi PKK Kelurahan Sukaraja Kota Prabumulih. Dalam organisasi PKK bidang ini merupakan bagian dari Kelompok kerja (POKJA) bidang ekonomi keluarga, sehingga dalam aktivitasnya POKJA ini bergerak dalam bidang pengembang unit usaha keluarga. Dalam pengembangan usaha UP2K Melati ini telah menjalan usaha di bidang pengelolaan hasil usaha pertanian khususnya pertanian Nenas yaitu membuat dodol, sirup, jelli dan kripik nanas, sebagaimana kita ketahui Nenas merupakan komoditi unggulan hasil pertanian Kota Prabumulih. UP2K Melati ini telah merupakan binaan dari Dinas Perindustrian dan perdagangan Kota Prabumulih dan PKK Kota Prabumulih.

Dalam pelaksanaan produksi keripik nenas, UKM Melati melibatkan bahan baku minyak goreng yang sangat berpengaruh terhadap kualitas produk olahan keripik nenas, selain itu kapasitas minyak yang digunakan cukup besar untuk vacuum frying kapasitas $5 \mathrm{~kg}$ dibutuhkan minyak $25 \mathrm{~kg}$ dan waktu pemakaian sampai $10 \mathrm{kali}$, sehingga perlu dianalisa terhadap karakteristik minyak jelantah dari proses pembuatan keripik nenas dengan metode penggorengan Vacuum Frying.

\section{METODELOGI PELAKSANAAN}

Untuk mengetahui apakah minyak jelantah atau minyak goreng bekas masih layak untuk dipakai berulang kali maka perlu dilakukan karakterisasi terhadap minyak goreng bekas tersebut dan dibandingkan dengan hasil karakterisasi minyak goreng yang belum dipakai untuk menggoreng.

Dalam pencapaian target dan luaran maka tahapan pelaksanaan yang akan dilakukan adalah:

1. Pengambilan sample minyak

2. Melakukan karakterisasi minyak jelantah

Pengujian Kadar Asam Lemak Bebas (ALB) dengan tahapan seperti berikut:

1. Ditimbang 2-5 gram sampel minyak jelantah kemudian menambahkan larutan 
metanol $95 \%$ dan 3 tetes indikator phenolphthalein.

2. Dititrasi dengan $\mathrm{NaOH} 0,1 \mathrm{~N}$ sampai terjadi perubahan warna menjadi merah muda.

3. Dicatat jumlah $\mathrm{NaOH}$ yang digunakan dan menghitung nilai ALB dengan rumus berikut: [9]

Kadar $\mathrm{FFA}=\left(\begin{array}{lllll}\mathrm{BM} & \mathrm{x} & \mathrm{V} & \mathrm{X} & \mathrm{N}\end{array}\right) /\left(\begin{array}{llll}10 & \mathrm{x} & \mathrm{m}\end{array}\right)$ Dimana:

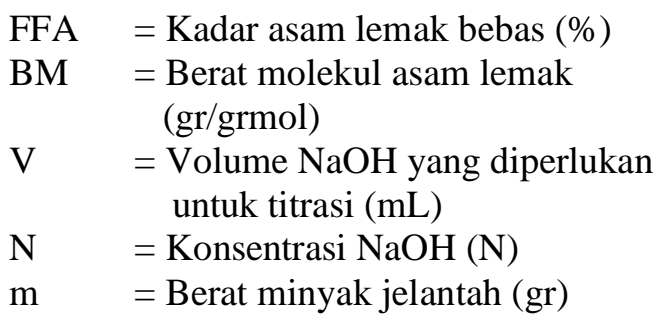

Penentuan kadar air

1. Dibersihkan dan dikeringkan cawan porselen di dalam oven dengan temperatur $105^{\circ} \mathrm{C}$ selama 60 menit, selanjutnya mendinginkan cawan tersebut dan menimbangnya.

2. Ditimbang 5 gr sampel biodiesel di dalam wadah porselen kemudian dimasukkan ke oven dengan suhu $105^{\circ} \mathrm{C} 1$ jam.

3. Mendinginkan dan menimbang kembali cawan porselen setelah 1 jam pemanasan.

4. Mengulangi percobaan hingga didapatkan berat tidak berubah lagi.

5. Menghitung kandungan air biodiesel menggunakan persamaan: [10]

$$
\begin{aligned}
& \text { Kadar air }(\%)= \\
& \frac{\text { Berat awwal-Berat kering }}{\text { Berat awal }} \times 100
\end{aligned}
$$

dimana:

Berat awal = Massa cawan + sampel sebelum pemanasan $(\mathrm{gr})$

Berat kering $=$ Massa cawan + sampel setelah pemanasan (gr)

\section{HASIL DAN PEMBAHASAN}

\subsection{Standar Mutu Minyak Jelantah}

Minyak jelantah yang digunakan harus memenuhi standar mutu seperti yang tertera pada Tabel 2, hal ini untuk menghindari kerusakan pada minyak jelantah yang digunakan berulang kali.

Tabel 2. Standar Mutu Minyak Jelantah

\begin{tabular}{ccc}
\hline No & Kriteria Uji & Persyaratan \\
\hline 1 & Bau & Normal \\
2 & Rasa & Normal \\
3 & Warna & Mudah jenuh \\
4 & Cita rasa & Hambar \\
5 & Kandunga air & Max 0,3\% \\
6 & Asam lemak bebas & Max 0,3\% \\
7 & temperatur asap & $200^{\circ} \mathrm{C}$ \\
8 & Angka iodine & $45-51$ \\
\hline
\end{tabular}

Minyak jelantah juga mempunyai sifat fisik dan kimia yang dapat dijadikan dasar dalam hal pemilihan untuk pemakaian minyak jelantah tersebut yang dapat dilihat pada Table 3.

Tabel 3. Sifat kimia dan fisik minyak jelantah

\begin{tabular}{ll}
\hline $\begin{array}{l}\text { Sifat Fisik Minyak } \\
\text { Jelantah }\end{array}$ & $\begin{array}{l}\text { Sifat Kimia Minyak } \\
\text { Jelantah }\end{array}$ \\
\hline $\begin{array}{l}\text { Warna kecoklatan } \\
\text { kekuning-kuningan }\end{array}$ & $\begin{array}{l}\text { Terjadi perubahan } \\
\text { menjadi asam lemak } \\
\text { bebas dan gliserol }\end{array}$ \\
Berbau tengik & $\begin{array}{l}\text { Akibat adanya kontak } \\
\text { antara oksigen dengan } \\
\text { minyak menyebabkan } \\
\text { terbentuk asam lemak } \\
\text { bebas dan gliserol } \\
\text { Adanya ikatan } \\
\text { adanya endapan } \\
\end{array}$ \\
& \begin{tabular}{l} 
minyak rantai C pada \\
\hline
\end{tabular} \\
\hline
\end{tabular}

\subsection{Karakteristik Minyak Jelantah}

Karakterisasi minyak jelantah dilakukan tehadap minyak jelantah yang diperoleh dari industri keripik nenas dari UKM Melati di Prabumulih. Sebelum dianalisa, dilakukan penyaringan untuk membersihkan kotoran pada minyak jelantah.

Setelah dilakukan karakterisasi terhadap minyak jelantah hasil pembuatan keripik nenas dengan metode vacuum frying, diperolah data seperti ini. 
Tabel 4. Analisa Karakteristik Minyak Jelantah

\begin{tabular}{|c|c|c|c|}
\hline No. & Parameter & Satuan & Nilai \\
\hline 1. & $\begin{array}{l}\text { Asam lemak } \\
\text { bebas }\end{array}$ & $\%$ & 4,32 \\
\hline 2. & Densitas & $\mathrm{gr} / \mathrm{cm}^{3}$ & 0,9191 \\
\hline 3. & Viskositas & $\mathrm{cSt}$ & 50,03 \\
\hline 4. & Titik nyala & ${ }^{\circ} \mathrm{C}$ & $>110$ \\
\hline 5. & $\begin{array}{l}\text { Kandungan } \\
\text { air }\end{array}$ & $\%$ & 0,8061 \\
\hline 6. & Angka asam & $\begin{array}{c}\mathrm{mg}- \\
\mathrm{KOH} / \mathrm{gr}\end{array}$ & 2,26 \\
\hline
\end{tabular}

Berdasarkan karakterisasi minyak jelantah memperlihatkan pada minyak jelantah mengandung asam lemak bebas yang tinggi yaitu 4,9 (syarat mak 0,3\%). Hal ini menunjukkan bahwa minyak goreng bekas penggorengan tidak bisa digunakan lagi setelah dipakai untuk menggoreng.

\section{KESIMPULAN}

Dari hasil analisis terhadap minyak jelantah hasil penggorengan keripik nenas dengan metode vacuum frying setelah disaring di UKM Melati Prabumulih diperoleh hasil yaitu nilai asam lemak bebas (FFA) $4,9 \%$ (syarat maksimum $0,3 \%$ ) dan nilai peroksida $1,8 \mathrm{Meq} / \mathrm{kg}$. Dengan demikian, minyak goreng bekas tidak bisa dipergunakan lagi untuk menggoreng.

\section{UCAPAN TERIMA KASIH}

Penulis mengucapkan terima kasih kepada Politeknik Negeri Sriwijaya yang telah mendanai pelaksanaan kegiatan pengabdian penugasan tahun 2018.

\section{REFERENSI}

[1] Gede, Niti. 2013. Minyak Jelantah Berubah Menjadi Sabun Mandi yang Harum. (online), diakses pada 20 Juni 2018.

[2] Adhari, Hamsyah, Yusnimar, dan Syelvia P. Utami. 2016. Pemanfaatan Minyak Jelantah Menjadi Biodiesel dengan
Katalis ZnO Presipitan Zinc Karbonat: Pengaruh Waktu Reaksi dan Jumlah Katalis. Riau: Jurusan Teknik Kimia S1, Fakultas Teknik, Universitas Riau.

[3] RAN Moulita, Rusdianasari, and L. Kalsum. 2019. Converting Waste Cooking Oil into Biodiesel using Microwaves and High Voltage Technology Converting Waste Cooking Oil into Biodiesel using Microwaves and High Voltage Technology. Journal of Physic: Conf.Ser. 1167(2019)

[4] J. U. Putra, L. Kalsum, and Y. Bow. 2018. Effect of DC Voltage on Prototype of Biodiesel Electrostatic Separator with Glycerin from Waste Cooking Oil. Indones. J. Fundam. Apply. Chem. 3(3). 89-93.

[5] BPS. 2014. Survei Sosial Ekonomi Nasional. 2009-2013.

[6] Kayun, Saraswati Purbo. 2007. Kajian Strategi Pengembangan Industri Biodiesel Berbasis Minyak Jelantah di Indonesia. Bogor: Institut Pertanian Bogor.

[7] Wijaya, K. 2011. Biodiesel dari Minyak Goreng Bekas. Jurnal Teknik Kimia 16, $1-10$.

[8] Suroso, Asri S. 2013. Kualitas Minyak Goreng Habis Pakai Ditinjau dari Bilangan Peroksida, Bilangan Asam, dan Kadar Air. Pusat Biomedis dan Teknologi Dasar Kesehatan Badan Litbangkes.

[9] Susumu, Rusdianasari, and S. Yusi. 2018. Biodiesel Production from Waste Cooking Oil using Electrostatic Method. Indones. J. Fundam. Apply. Chem. 3(3). 71-76.

[10] Yusmartini, E.S. and Rusdianasari. 2016. Separation Process Biodiesel for Waste Cooking Oil using Ultrafiltration Membranes. Proceeding Forum in Research and Technology (FIRST), pp. B10-B13. 